\title{
INFLUENCE OF HYDROGEN ON THE WEAR RESISTANCE OF MATERIALS IN THE FRICTION COUPLES OF BRAKING UNITS
}

\author{
M. V. Kindrachuk, ${ }^{1}$ D. A. Vol'chenko, ${ }^{2}$ N. A. Vol'chenko, ${ }^{4}$ \\ N. M. Stebeletskaya, ${ }^{5}$ and A. V. Voznyi ${ }^{2,3}$
}

UDC 629.113: 621.2 .082 .18

\begin{abstract}
We describe a method for the industrial investigation of the friction couples of band-block brakes of drill winches preventing hydrogen release from the steel surface of the pulley rim by the electric field with like positive charges restricting the motion of hydrogen ions.
\end{abstract}

Keywords: band-block brake, improved friction couples, materials of friction elements, hydrogeninduced wear, wear resistance of materials, operating parameters, energy levels.

Hydrogen-induced wear as one of the processes leading to the fractures of the surfaces of metallic friction elements under conditions of electrothermomechanical friction is caused by the phenomenon of breaking of hydrocarbon bonds with hydrogen release followed by its diffusion into the surface layers of steels and, hence, their hydrogen embrittlement [1-5]. In particular, it was established that the sizes of the products of wear after the hydrogenation of specimens are much larger than prior to the hydrogenation (the linear sizes are different by 5-6 times) [1-3]. In addition, the products separating under the conditions of rolling or sliding friction have larger areas of seizure and damaging than for the nonhydrogenated specimens. However, their influence on the electrothermomechanical friction and wear of friction couples has not yet been described in the literature.

Therefore, the aim of the present work is to study the influence of hydrogen on the process of wear in the friction couples of braking units used in the machine-building industry and to decrease the hydrogen-induced wear in the zone of friction interaction for disconnected friction couples by means of creation of the main and residual positive electric fields between their working surfaces.

\section{Materials and Methods of Investigations}

We consider specific features of construction and the operation of improved friction couples in the bandblock brake of a drilling winch (Fig. 1a, b). The friction pads 3 were mounted on the braking bands 2 by attaching one end (from the outcoming branch of the band) to balancer 11 and the other end (from the incoming branch) to the crank pins 6 and 9 of crankshaft 10 .

The serial band-block brakes of drilling winches operate in the following way: Crankshaft 10 rotates as a result of a motion of the lever handle 1 . As a result, the drill operator tightens the braking bands 2 with friction

\footnotetext{
${ }^{1}$ National Aviation University, Kiev, Ukraine.

2 Ivano-Frankivs'k National Technical University of Oil and Gas, Ivano-Frankivs'k, Ukraine.

${ }^{3}$ Corresponding author; e-mail: Anarki1@i.ua.

${ }^{4}$ Kuban' State Technological University, Krasnodar, Russian Federation.

5 Berezhany Agricultural Institute, Berezhany, Ukraine.
}

Translated from Fizyko-Khimichna Mekhanika Materialiv, Vol.53, No.2, pp.135-141, March-April, 2017. Original article submitted December 23, 2016. 


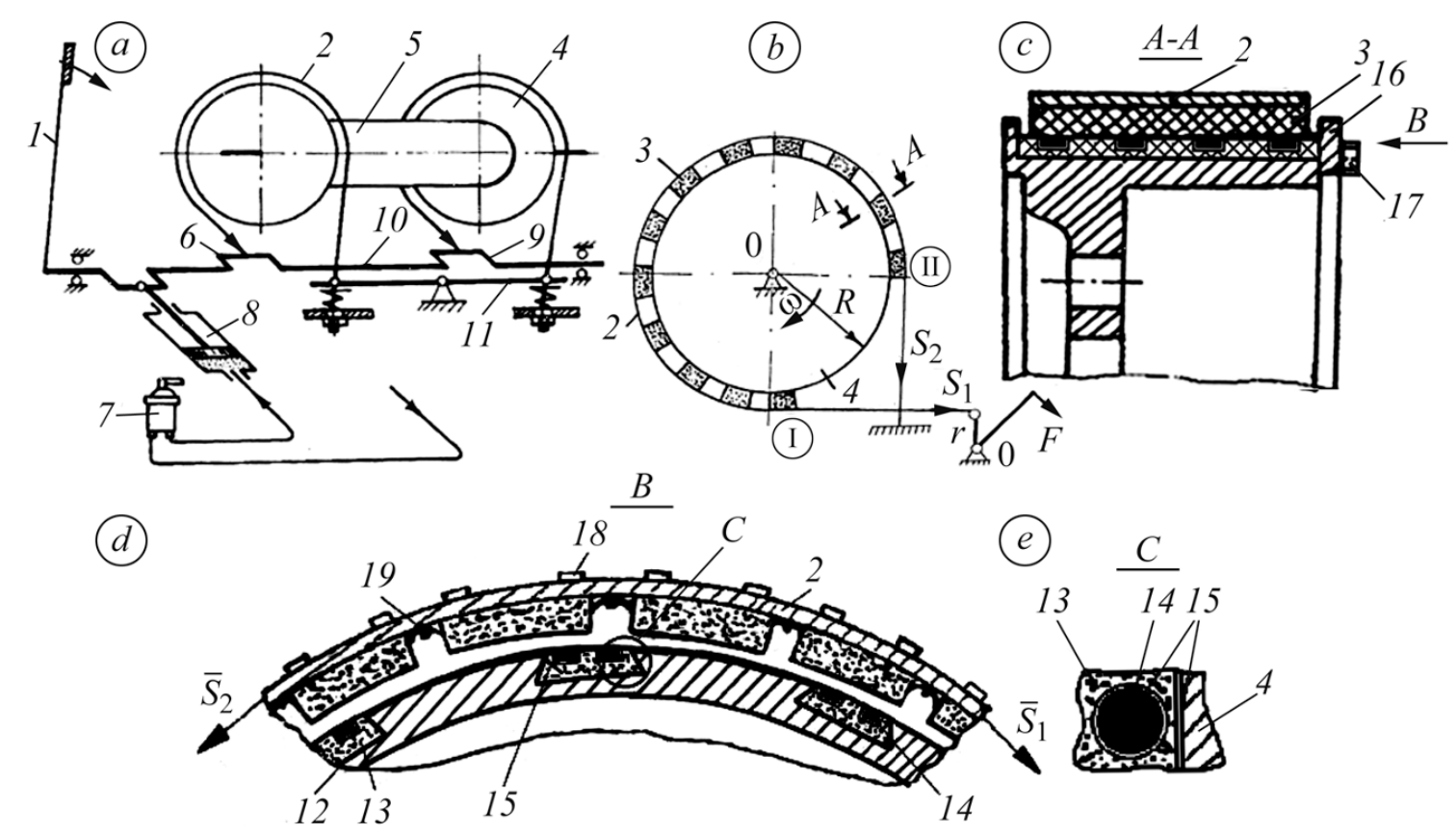

Fig. 1. Kinematic schemes of the band-block brake of a drilling winch (a,b); transverse and longitudinal sections of the friction unit of the brake (c,d); heat insulation of the friction element, tablets (inserts) (e): (1) brake control lever; $(2,3)$ braking bands with pads; $(4,16)$ braking pulley with removable flange; $(5)$ winch drum; $(6,9,10)$ crank pins of the crankshaft; $(7,8)$ valve of the pneumatic cylinder; (11) balancer; (12) dovetail-type longitudinal grooves; (13) additional friction elements made of FK-24A retinax; (14) teflon-4 tablets; (15) thermal insulation; (17) fixing screws; (18, 190 fixing and spacer strips.

pads 3 and they sit onto the rims of the braking pulleys 4 . The braking pulley 4 has longitudinal grooves 12 of the dovetail-type, with additional friction elements 13 made of FK-24A retinax mounted along the perimeter of the rim from its free edge with constant steps. Tablets 14 made of teflon-4 (polytetrafluoroethylene) are placed along the length of these elements. Friction elements are separated from the rim of pulley 4 and from the tablets by the thermal insulation 15 . In this case, the right flange 16 is removable. It is fixed along the perimeter of the rim end of pulley 4 with screws 17. The friction pads 3 are attached to the braking band 2 with the help of strips 18. The spacer strips 19 are mounted between the pads along the perimeter of the braking band 12 .

We use the following notation: $R$ is the radius of the working surface of the rim of braking pulley; $r$ is the radius of the crankshaft crank; $\omega$ is the angular velocity of rotation of the pulley; $\bar{S}_{1}$ and $\bar{S}_{2}$ are the tensions of the incoming and outcoming branches of the braking band, respectively; $F$ is the working force on the control lever of the brake, and $q^{+}$and $q^{-}$are positive and negative charges of the electric field.

\section{Results and Discussion}

The process of friction interaction of the microasperities of friction couples of the band-block brake in the mode of high sliding velocities and specific loads is accompanied by the generation of electric currents and the accumulation of heat flows. As a result, the surface temperatures and their gradients increase. At temperatures higher than $400^{\circ} \mathrm{C}$, the binding component (formaldehyde resin) is burned out from the surface layers of the friction pad. This results in the formation of a corrosive hydrogen-containing medium creating favorable conditions for the tribocracking accompanied by the release of free hydrogen. Hydrogen interacts with the surface and subsurface layers of materials (silicon, sulfur, white phosphorus, titanium, iron, etc.) of friction couples and 
forms unstable hydrides. In addition, the surface layers of microasperities undergo the electron-ion heat-induced polarization accompanied by a sharp jump of the temperature gradient across the thickness of the surface layer. As a result, the hydrogen-induced wear of the surface layers of the friction materials of friction couples of the band-block brake of drilling winch significantly intensifies. This is explained by the intense hydrogen release from the polymeric pad in the friction zone due to the tribocracking guaranteeing its continuous supply to the surface layer of the steel rim of the pulley; by the absorption of hydrogen on the surfaces of metallopolymeric friction couples; by its diffusion into the deformed surface layer of the pulley rim depending on the stress gradients, and by the specific type of surface fracture caused by the simultaneous development of a large number of nuclei of microcracks over the entire contact zone.

The property of FK-24A polymeric materials and tablets (inserts) made of teflon-4 in the FK-24A materials to "select" charges is probably connected with the ability to attach ions and electrons to their surfaces with the saturation of the double electric surface layers of the polymer. As a result of the friction interaction of the FK-24A and "FK-24A-tablets-inserts made of teflon-4" friction couples, the first material becomes positively charged and plays the role of the donor of electrons due to its higher dielectric permittivity than for the second material, which becomes negatively charged and plays the role of the acceptor of electrons.

A completely different picture is observed in the case where the binding components are burned out from the surface layers of these materials. The water liberated from these layers is characterized by a high dielectric permittivity. In this case, the FK-24A friction elements with tablets-inserts of teflon-4 turn into donors of electrons due to the lower admissible temperature for their components. They saturate the double electric surface layer of the rim of braking pulley rim and, hence, increase the potential difference between its "35KhNL steelFK-24A with tablets-inserts" sections. The surface temperature gradients in the subsurface layer of the pulley rim noticeably exceed the gradients in depth. In addition, the positive electric field blocks hydrogen ions $\left(\mathrm{H}^{+}\right)$ by preventing their penetration into the subsurface layer.

A similar situation is observed in the surface and subsurface layers of the FK-24A friction material. The admissible temperature of its components is higher. The FK-24A material turns into a donor of electrons for the components and saturates the double electric layers [fluid (one layer) and the surface layer of the pad (second layer)]. Thus, the potential drop is formed between these layers. As a result, the positive electric field of the surface layers of the pads on the braking band becomes more intense.

The energy levels formed on the working surfaces of improved friction couples of the brakes are determined by the contact electrothermomechanical processes caused by the collisions of microasperities of the metallopolymeric couples of the tribosystem. As a result of plastic deformation at the sites of contact, we observe the generation of electric currents until their discreteness is preserved and the actual contact area is small as compared with the nominal area $\left(A_{r} \leq A_{0}\right)$. Thus, an electric field appears as a result of summation of the components of currents generated in the spots of friction contact. Then, for $A_{r} \geq A_{0}$, a nonsteady thermal flux is accumulated and leads to the formation of an inhomogeneous temperature field.

In the presence of friction between the polymer and the metal (Fig. 2), unlike the case of breaking of contact between the metals or their friction, the process of charging of the surface gradually runs in the course of wear of the spots of contact of microasperities as a result of the increase and breaking of contacts between the "spots of charging." In this case, significant amounts of charges are accumulated.

The surface can receive no charge in the case of interaction of microasperities of the metallopolymeric triboconjugation if the values of the work functions $(W)$ of electrons and ions from the metal and polymer are equal. In this case, the polymer is called electrophobic, unlike electrophilic polymers electrified both for $W_{M}>W_{P}$ and for $W_{M}<W_{P}$. On the surfaces of electrophilic materials [in the case of burning out of their binding components from the surface layers of the tablets (inserts), polymeric elements, and pads], we observe the formation of a thin layer of moisture facilitating the process of charging. 


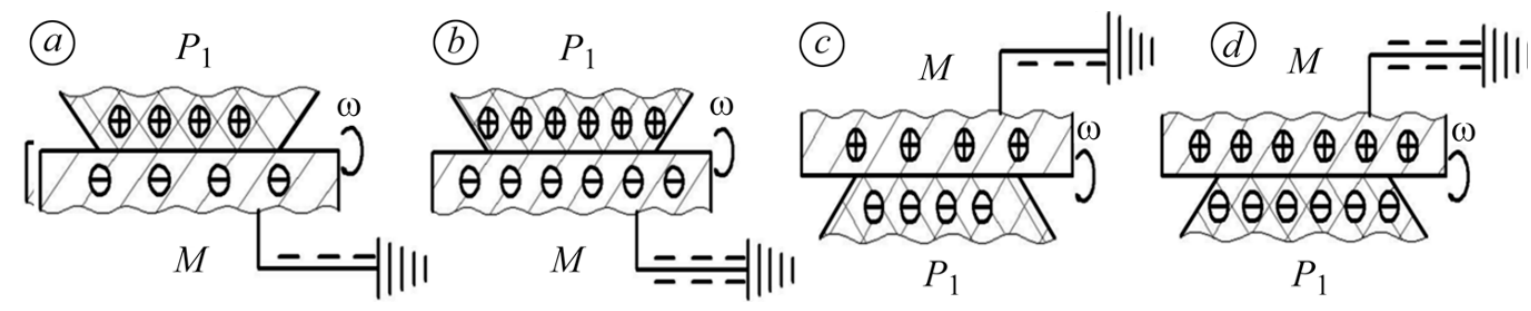

Fig. 2. Accumulation of electric charges in the "polymer $\left(P_{1}\right)-$ metal $(M)$ "(direct) $(\mathrm{a}, \mathrm{b})$ and "metal $(M)-\operatorname{polymer}\left(P_{1}\right)$ " (reverse) $(\mathrm{c}, \mathrm{d})$ friction couples during their friction interaction.

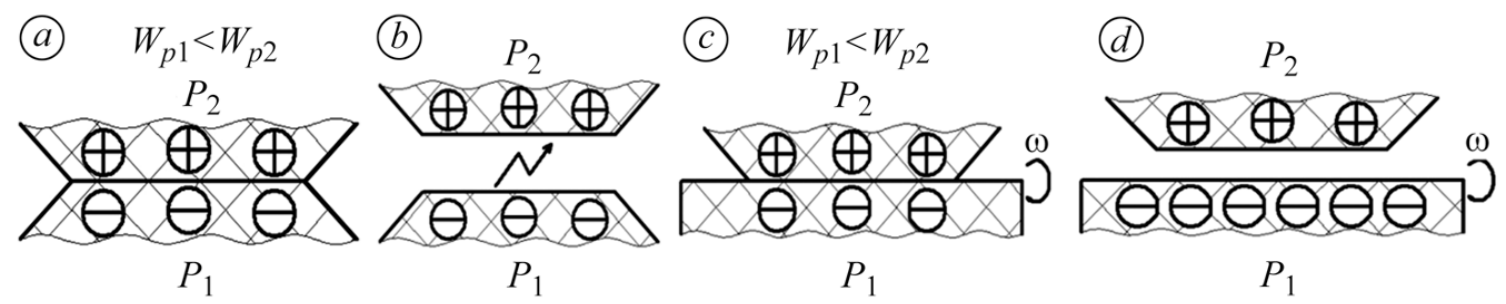

Fig. 3. Accumulation of electric charges in the "polymer $\left(P_{1}\right)$-polymer $\left(P_{2}\right)$ " friction couples under the conditions of static (a) and friction (c) interaction and in the opened state $(\mathrm{b}, \mathrm{d}): W_{P_{1}}$ and $W_{P}$ are the Fermi levels of the surfaces of the first and second polymeric pads.

In the case of contact of two films of polymeric materials $\left(P_{1}\right)+\left(P_{2}\right) \quad$ (Fig. 3) without friction, the charge density formed on their surface is given by the formula

$$
\sigma_{S}=\frac{e\left(W_{P_{1}}-W_{P_{2}}\right)}{1 / \rho_{S_{1}}+1 / \rho_{S_{2}}},
$$

where $W_{P_{1}}$ and $W_{P_{2}}$ are the Fermi levels of the surfaces of the first and second polymeric pads and $\rho_{S_{1}}$ and $\rho_{S_{2}}$ are the densities of surface states of the polymeric pads and friction elements with tablets (inserts).

The first pad is charged positively for $W_{P_{1}}>W_{P_{2}}$ and negatively for $W_{P_{1}}<W_{P_{2}}$ (Fig. 2). A sequence of polymers arranged so that every next polymer in it is charged negatively as compared the previous polymer in the case of their contact is called triboelectric. The position of the polymer in the triboelectric sequence characterizes its susceptibility to charging with positive or negative charges. The instantaneous breaking of contact between two spots of microasperities with charges $+q$ and $-q$ leads to the formation of a high potential drop. The physicomechanical properties of some materials of friction couples used in the brakes are presented in Table 1.

The $\mathrm{SiH}_{4}, \mathrm{PH}_{3}$, and $\mathrm{H}_{2} \mathrm{~S}$ hydrides are characterized by certain numbers of hydrogen atoms per one atom of the element in their molecules. Starting from silicon, the formation of molecular compounds shows that the elements take the electron configuration of the subsequent inert gas (argon, which is the last element of the third period of the Periodic Table) and form common electron pairs with hydrogen atoms.

The process of hydrogenation of the metal promoting the embrittlement and dispersion of the deformed friction layer can be explained by the results of investigations of the influence of the mechanism of electron-and-ion heat-induced polarization in the course of electrothermomechanical friction on the transfer processes in the metal-polymer metallopolymeric pairs. Hydrogen is released in the case of activation of the reaction of dehydrogenation of hydrocarbons of the surface layers of polymeric pads by the electrothermomechanical friction. 
Table 1. Characteristics of Steels of the Braking Pulleys

\begin{tabular}{|c|c|c|c|c|c|c|}
\hline \multicolumn{2}{|c|}{ Compositions of steels, wt.\% } & \multicolumn{2}{|c|}{ Valence } & \multicolumn{2}{|c|}{$\begin{array}{l}\text { Predominant type of } \\
\text { intrinsic conductivity }\end{array}$} & \multirow{2}{*}{ Hydrides } \\
\hline $35 \mathrm{KhNL}(\mathrm{I})$ & $35 \mathrm{KhML}$ (II) & I & II & I & II & \\
\hline $2.20-0.42 \mathrm{Si}$ & $0.2-0.4 \mathrm{Si}$ & \multicolumn{2}{|c|}{4} & \multicolumn{2}{|c|}{ Semiconductor } & $\mathrm{SiH}_{4}$ \\
\hline Up to $0.3 \mathrm{Cu}$ & - & 1.2 & - & $n$ & - & - \\
\hline $0.4-0.9 \mathrm{Mn}$ & $0.4-0.9 \mathrm{Mn}$ & \multicolumn{2}{|c|}{$2,3,4,5,6,7$} & \multicolumn{2}{|c|}{$n$} & - \\
\hline $0.7-0.9 \mathrm{Ni}$ & - & 2 & - & $n$ & - & - \\
\hline$\leq 0.04 \mathrm{P}$ & $\leq 0.04 \mathrm{P}$ & \multicolumn{2}{|c|}{3} & \multicolumn{2}{|c|}{$n$} & $\mathrm{PH}_{3}$ \\
\hline $0.5-0.8 \mathrm{Cr}$ & $0.8-1.1 \mathrm{Cr}$ & \multicolumn{2}{|c|}{3,6} & \multicolumn{2}{|c|}{$p$} & - \\
\hline$\leq 0.04 \mathrm{~S}$ & $\leq 0.04 \mathrm{~S}$ & \multicolumn{2}{|c|}{$2,4,6$} & \multicolumn{2}{|c|}{ Dielectric } & $\mathrm{H}_{2} \mathrm{~S}$ \\
\hline- & $0.3-0.4 \mathrm{C}$ & - & 2,4 & - & Dielectric & - \\
\hline- & $0.2-0.3 \mathrm{Mo}$ & - & 6 & - & $p$ & - \\
\hline $36.62-97.82 \mathrm{Fe}$ & $97.82-98.02 \mathrm{Fe}$ & \multicolumn{2}{|c|}{1,3} & \multicolumn{2}{|r|}{$n$} & $\mathrm{FeH}, \mathrm{FeH}_{3}$ \\
\hline
\end{tabular}

It is supplied by the products of thermal destruction of the organic binders (e.g., various resins) and also by moisture appearing on the working surface of the metallic friction element in the tribological system.

The diffusion flow of hydrogen formed on the working surface of the steel friction element is directed to the zone with the maximum local temperature. This zone is located at a certain depth from the friction surface (displacement of the zone with maximum temperature), where hydrogen is dissolved. Thus, hydrogen absorbed by the metal can dissociate. Indeed, the uniquely small size of a proton $\left(1 \cdot 10^{-13} \mathrm{~cm}\right)$ and its opposite charge as compared with the metal help significantly facilitate its penetration into the lattice.

The improved friction couples were tested in the band-block brakes of U2-5-5drilling winches in the course of their natural or forced cooling during the descent of a stand of drill pipes in a bore hole down to a depth of $4108 \mathrm{~m}$. The stand consisted of 102 sections six of which were heavy-weight drill pipes, while the remaining sections were low-weight pipes. The total weight was $962.23 \mathrm{kN}$. In this case, the ambient temperature was $20.2^{\circ} \mathrm{C}$ and the pressure was equal to $0.0942 \mathrm{MPa}$.

It was discovered (Table 2) that, in the case of preservation of numerous basic engineering characteristics of an analog, the proposed friction couples make the energy intensity of wear of the pads 1.3 times lower for the given modes of their loading affecting the potential drop between the microasperities (Table 3 ).

The highest potential drop was recorded in the "FK-24A-FK-24A + teflon-4" friction couple because the fraction of tablets (inserts) in the area of the friction element made of FK-24A does not exceed 14\%. Moreover, they have practically no influence on the dielectric permittivity of the material of friction element. This promotes 
Table 2. Triboelectric and Operating Parameters of the Improved Band-Block Brake of a U2-5-5 Drilling Winch

\begin{tabular}{|c|c|c|c|c|c|c|c|c|}
\hline \multirow{2}{*}{$\begin{array}{l}\text { Friction } \\
\text { couple }\end{array}$} & \multicolumn{2}{|c|}{ Sign of charge } & \multicolumn{6}{|c|}{ Operating parameters } \\
\hline & + & - & \multirow{3}{*}{$\begin{array}{c}\text { Friction } \\
\text { force } \\
F_{f}=\left(S_{1}-S_{2}\right) \\
\mathrm{kN}\end{array}$} & \multirow{3}{*}{$\begin{array}{c}\text { Dynamic } \\
\text { friction } \\
\text { coefficient, } \\
f\end{array}$} & \multicolumn{2}{|c|}{$\begin{array}{l}\text { Temperature } \\
\text { gradients }\end{array}$} & \multirow{3}{*}{$\begin{array}{c}\text { Braking } \\
\text { moment } \\
M_{f}, \\
\text { kNm }\end{array}$} & \multirow{3}{*}{$\begin{array}{c}\text { Energy wear } \\
\text { intensity of } \\
\text { the pads } I \text {, } \\
\mu \mathrm{g} / \mathrm{J}\end{array}$} \\
\hline $\begin{array}{c}\text { Two } \\
\text { chemically }\end{array}$ & \multicolumn{2}{|c|}{$\begin{array}{l}\text { Density of } \\
\text { elements }\end{array}$} & & & Surface, & Bulk $t_{v}$ & & \\
\hline elements & High & Low & & & & & & \\
\hline $\begin{array}{c}\text { FK-24A- } \\
\text { 35KhNL steel }\end{array}$ & $\begin{array}{l}\text { Poly- } \\
\text { mer }\end{array}$ & Metal & 259.6 & 0.38 & $40.0-60.0$ & $6.0-15.0$ & 188.2 & 2.5 \\
\hline \multirow{2}{*}{$\begin{array}{c}\text { FK-24A- } \\
\text { FK-24A + } \\
\text { teflon- }{ }^{1}\end{array}$} & \multicolumn{2}{|c|}{$\begin{array}{c}\text { Dielectric } \\
\text { permittivity of } \\
\text { the polymer }\end{array}$} & \multirow[t]{2}{*}{200.98} & \multirow[t]{2}{*}{0.3} & \multirow[t]{2}{*}{$4.5-8.5$} & \multirow[t]{2}{*}{$2.0-3.0$} & \multirow[t]{2}{*}{159.44} & \multirow[t]{2}{*}{1.35} \\
\hline & High & Low & & & & & & \\
\hline \multirow{2}{*}{$\begin{array}{l}\text { 35KhNL steel- } \\
\text { 35KhNL steel }\end{array}$} & \multicolumn{2}{|c|}{$\begin{array}{l}\text { Hardness of } \\
\text { the metal }\end{array}$} & \multirow[t]{2}{*}{102.5} & \multirow[t]{2}{*}{0.15} & \multirow{2}{*}{\multicolumn{2}{|c|}{$30.0-100.015 .0-20.0$}} & \multirow[t]{2}{*}{74.3} & \multirow[t]{2}{*}{0.3} \\
\hline & High & Low & & & & & & \\
\hline \multicolumn{3}{|c|}{$\begin{array}{l}\text { Results of experimental studies } \\
\text { of improved friction couples }\end{array}$} & 265.0 & 0.4 & $30.0-50.0$ & $4.5-13.0$ & 195.0 & 1.95 \\
\hline
\end{tabular}

Comments: 1 . The surface area of the tablets (inserts) with friction elements is equal to $(45-75)^{\circ}$ of the arc of the band with pads enclosing the pulley rim.

Table 3. Potential Drop between the Microasperities of Friction Couples of the Band-Block Brake of a U2-5-5 Drilling Winch

\begin{tabular}{c|c|c|c}
\hline Friction couples & $\begin{array}{c}\text { FK-24A - } \\
\text { 35KhNL steel }\end{array}$ & $\begin{array}{c}\text { FK-24A - } \\
\text { FK-24A + teflon-4 }\end{array}$ & $\begin{array}{c}\text { 35KhNL steel - } \\
\text { 35KhNL steel }\end{array}$ \\
\hline Potential drop $\Delta V, \mathrm{mV}$ & 0.47 & 0.74 & 0.27 \\
\hline
\end{tabular}

the generation of positive charges in this friction couple and, hence, leads to the appearance of a positive electric field which prevents the adsorption of hydrogen ions in the subsurface layers of friction couples in their closed and opened states. This circumstance plays the crucial role in decreasing the hydrogen-induced wear of the friction couples of brakes. 
Depending on the diameter and width of the rim of the pulley race, we determine the area of tablets (inserts) and teflon-4 introduced in the friction elements made of the FK-24A polymeric material and placed along the perimeter of the pulley rim.

\section{CONCLUSIONS}

The proposed method enables one to significantly increase the wear resistance of the working surfaces of friction couples of the band-block brake of a drilling winch by decreasing the intensity of hydrogen-induced wear in these couples in the zone of friction interaction. For the open friction couples, this can be attained by creating the main and residual electric fields with the help of additional friction couples.

\section{REFERENCES}

1. A. A. Polyakov (editor), Protection against Hydrogen Wear in Friction Units [in Russian], Mashinostroenie, Moscow (1980).

2. D. N. Garkunov, Triboengineering (Wear and the Absence of Wear) [in Russian], Moscow Agricultural Academy, Moscow (2001).

3. V. A. Kolesnikov, A. V. Kalinin, A. I. Balitskii, and Ya. V. Khmel', "Necessity of taking into account for the influence of hydrogen on the wear resistance of materials in the braking friction couples of the cars," Visn. SNU im. V. Dalya, No. 11(141), 62-65 (2009).

4. O. I. Balyts'kyi, V. O. Kolesnikov, and P. Kawiak, "Triboengineering properties of austenitic manganese steels and cast irons under conditions of sliding friction," Fiz.-Khim. Mekh. Mater., 41, No. 5, 55-60 (2005); English translation: Mater. Sci., 41, No. 5, 624-630 (2005).

5. O. I. Balyts'kyi, V. O. Kolesnikov, Y. Eliasz, and M. R. Havrylyuk, "Specific features of the fracture of hydrogenated high-nitrogen manganese steels under conditions of rolling friction," Fiz.-Khim. Mekh. Mater., 50, No. 4, 110-116 (2014); English translation. Mater. Sci., 50, No. 4, 604-611 (2015). 